tinged with blood for the first thirty hours. The symptoms of chronic cystitis, although lessened, still persisting, the bladder was on several occasions washed out with a solution of quinine. She left quite well for the country town where she usually resided in the middle of November. Weight of fragments 500 grains; nature of calculus uric acid.

CASE 16.-Haryunza $\mathrm{N}-$, a Hindoo, aged thirty, was admitted into the J. J. Hospital on January 3rd, 1882, suffering from stone in the bladder. Duration of disease nine months. A weak, sickly-looking man, in great pain; the urine constantly dribbling, and sleep, even with opiates, almost impossible owing to the frequency of micturition. Urine alkaline, on cooling deposited muco-pus. On the 14th of January the operation of litholapaxy was performed, the sitting lasting forty-five minutes. Very slight reaction followed. Urine passed normally from the first; all symptoms of subacute cystitis disappeared without special treatment. He was discharged well on January 22nd. Weight of stone 360 grains; nature of calculus mixed oxalate of lime and phosphates.

\section{A STUDY OF DISEASED JOINTS AT THE BATH MINERAL WATER HOSPITAL.}

BY J. KENT SPENDER, M.D. LOND., PHYSICIAN TO THE HOSPITAL.

FOREIGN writers have often reproached English balneologists with the little which they have written about the spas of Great Britain and Ireland, and the methods of practice which have been found most successful. The reproach is partly true ; but the fact is that the era of quaint speculation about baths has passed away, and with a dislike to fanciful theories we are now quietly accumulating observations and experience. If, as Dr. Macpherson says, "bath physicians are very sparing in communicating accounts of their practice," it is because they are engaged for a time in recording accurately what they see, and not because they wish to keep a secret nostrum all to themselves. A subject which is so easily clouded with a fog of empiricism needs to be prosecuted with all the canons of scientific rigour. The work cannot be done in a hurry. The least suspicion of "exaggerated representations of medical efficacy" rouses distrust or downright unbelief, and men refuse to see the most plain facts or the most legitimate inferences. Without sentimental pity we must tear aside all the romance and wonder and charm under which the truth has got embedded, and try to get at the right therapeutic doctrine. Let us remember the terse saying of Sir George Gibbes eighty years ago, that eagerness in recommending a medicine is often the surest means of destroying confidence in it.

Every mineral water has its medical traditions, and from time immemorial weak, swollen, and crooked joints have been sent to the thermal springs of Bath. My theme is medico-chirurgical, and within the domain of both physician and surgeon : of the physician by reason of constitutional causes; of the surgeon because of certain outward effects. But what we have to treat at our Mineral Water Hospital is not so much morbid action actually going on as structural damage already done, and which we try (so far as we can) to undo. From this fact arise certain difficulties. First of al a diagnosis has to be made, and this, though mainly chirurgical, is surrounded by medical influences and qualifications. A number of constitutional or diathetic causes may make one or more joints weak, or crooked, or swollen. We may learn from any text-book that the surgical pathology of rheumatism consists in contraction of ligaments, adhesions between articular surfaces, and chronic effusion within the synovial membrane; that the toxæmia of gout causes a deposit of urate of soda in the cartilage of a joint, which may even encroach on the adjacent bone; and that the disease called nodular (or rheumatoid) arthritis means a specific ulceration of bone and its cartilaginous covering, with the formation of knotty masses of new bone around the edges of an articulation. All this is clear enough when the medical history interprets the surgical pathology. If we trace the lineage of these three type-forms of joint lesion, it may be said that rheumatism is a blood and a nerve storm together; gout is the result of albuminoid stuff which has gone wrong; and nodular arthritis is a special nutritive disturbance of the joint-ends of bones. ${ }^{2}$ Now if Nature would obligingly send us only these three forms, precisely marked, and never letting us be in any doubt, I believe that, so far as this matter goes, we should be able to construct a science of balneo-therapeutics as rational and accurate as any other branch of the healing art. We should gather some of the data, moreover, for declaring in what ways a thermal spring may be in jurious; for that it can do great good, if properly used, implies the correlative fact that it may in some cases do great harm. It was one of Sydenham's wise aphorisms that the "free bounty of Nature must not be turned to our harm, even if we have not learned to do good with it," and both the profession and the public have a right to know how and when a mineral water becomes in a therapeutic sense a noxious thing. The oracular vagueness of some "bath physicians" on this point in bygone days is the cause of the mysticism and quackery which have surrounded the medical application of thermal waters.

But Nature is not bound within the confines of pathological diagrams. There are cases which positively decline to be put in any group, examine them how we will. Shall we call them for the present examples of simple "chronic arthritis ?" This sounds like evading a difficulty, but really it is a lawful and provisional hypothesis for helping us out of it. The borderland of one pathological territory is sometimes inextricably confused with that of its neighbour ; the same parts may be successively attacked by quite different morbid processes, so that all distinctive features of the original disease are effaced. It may be, therefore, quite scientific to give the generic name " arthritis" to a specimen of joint disease, and to wait a little while before adding the specific appellation. Just as a so-called gouty person can suffer from non-gouty complaints, so a state of joint in which a morbid action was first started by gout may lose its early characteristics and become clinically a swollen segment of a limb, injured in its proper functions of movement and support. Then it is said by Mr. Jonathan Hutchinson that gout and rheumatism are often present together. "Rheumatism occurs without gout, but gout is seldom present with out rheumatism. Sometimes the two exist side by side, and attack the same patient at different times; but more frequently they become mixed, and produce a hybrid disease." Other cases seem to begin in one form, and then to glide into another; thus rheumatoid (or nodular) arthritis is often a graft on what is left after acute rheumatism, or a long subfebrile rheumatic condition; as if the affected parts became prone to the attacks of another disease essentially different from rheumatism, but infesting the same structures. These considerations must be an apology for the fact that we are now and then puzzled by the cases of joint disease presented to us at the Bath Mineral Water Hospital, and that we cannot always offer a ready diagnosis and prognosis, or an immediate opinion whether the thermal waters will do any good. The intellectual mist that hangs over some of these chronic maladies is not always dispersed by the answers of an intelligent patient, or by the study of a careful medical history. Out of a homely metaphor Mr. Hutchinson has provided a scientific shelter for us in our difficulties ; brandy-and-water, he says, when mixed still remain brandy-and-water; the brandy does not become water or the water brandy. In like manner there are people who are suffering partly from rheumatism and partly from gout, mixed in proportions which defy the keenest clinical analysis, but each has produced its own separable share of textural damage.

Now, if we are to study with any profit the "mixed cases" which undoubtedly exist in significant numbers, we must first grasp with distinctness the clinical features of the type-forms. The inside of a joint is as much hidden as the viscera of any of the great cavities of the body; and for a satisfactory diagnosis of most old joint lesions there are needed a trained eye and a delicate manipulation. The abiding effects of rheumatism are seen in the atrophied and feeble ligaments, the fibrous adhesions (causing flexion and

1 The term lithæmia, or lithiasis, sanctioned by Dr. Andrew Clark and the late Dr. Murchison, should be taken to mean an imperfect gout, or a state which may be gout some day.

2 The probable nervous origin of this disease, and its etiological alliance with locomotor ataxy, have been insisted on by Dr. Ord. In private letter to me, Dr. Little of Ben Rhydding suggests "neurotic arthritis" as a proper title, and says that it has been sanctioned "by $\mathrm{Dr}$ Clifford Allbutt and other scientific friends."

à Brit. Med. Jour., Aug 27 th, 1881 
more or less distortion of a joint), and the rigidity of the tendinous cords which are inserted into the joint-ends of the bones. Look at a finger deformed by rheumatism, and it is seen to be bent in one or more of its joints, zigzag fashion, but no joint is specially enlarged. Now turn to another hand, the owner of which may be more eager to talk about his "rheumatics," and the characters of nodular or rhenmatoid arthritis in an early stage are clearly written. Several finger joints (particularly the junction of the first and second phalanges) are obviously larger than usual ; the synovial membrane feels thickened, and the ends of the bones are expanded, and here and there may be the sensation of "dry grating." If there be any impediment to the movement of a joint this arises not from adhesions, or from contraction of ligaments and fascia, but from the structural alteration of the parts preventing freedom of play. A third patient may be supposed to exhibit the ultimate ravages of gout; the small joints are bulging; little white points may be seen about the palmar ends of the fingers and a very common deformity (says Dr. Garrod) is a swellino over the carpo-phalangeal joints of the index and middle fingers. Sometimes, however, there is no enlargement of any joint, but the hands are rendered nearly useless by a peculiar and angular distortion of the fingers, resembling the disfigurement of advanced nodular arthritis. Our diagnosis of the medical cause of all this surgical pathology may be corrected or cunfirmed by an examination of the larger joints, by looking at the general diathetic state, and by a judicial estimate of many surrounding circum stances, most of which would help to guide the sound practical physician. We are discussing now, let me repeat, not the morbid anatomy of the deadhouse, which we can verify with the scalpel, but the phenomena of living patients.

It is an object of this paper to defend the ancient doctrines and protect some of the old landmarks. There are many points of diagnostic relationship between the acute phases of rheumatism and the destructive forms of slow arthritis; but gout is, so to speak, only accidentally an arthritis at all. It is not gout because of the arthritis, but arthritis because the joint-structures are such convenient nests for the deposit of gouty material. The amount of rheumatism is declared by the amount of arthritis, but there may be much gout with little arthritis, for the gout has spent itself in other ways. In discussing diseases of the skin we do not talk of a "cutaneous diathesis ;" we do not find any help from such a term when we are in diagnostic difficulties. Sometimes lichen with its fine scales closely resembles psoriasis, and psoriasis may now and then be hardly distinguisable from dry eczema. How often are the ravages of lupus like those of syphilitic gummata. But we know that rigid inquiries about its origin and progress will soon determine what a skin disease is if we have patience to work the matter out and are not guided solely by present appearancea. And when we recollect to what strenuous wear and tear the joints are exposed, especially among our working classes, we cannot wonder that very varied diseases display their phenomena in joint structures, because over-use makes them proportionately vulnerable.

How do these speculations help the study of diseases of joints? In many ways. Going in logical order through the symptoms, general and local, we gain a clue to what has been the matter with a joint, and can follow it with the precision obtained by experience and knowledge. For example, we are confronted with a big knee, which can be neither properly flexed nor extended, and is an engine of weakness rather than of strength in its offices of movement and support. We examine the joint with anatomic scrutiny, and note where and to what extent it is enlarged, and (very important) at what spots it is painful, $\alpha r$ if pressure in any direction causes pain. Swelling and thickening of synovia membrane should be always distinguished from broadening of the joint ends of the bone; and the protrusion of the bursa in the popliteal space, which (according to Mr Holden) sometimes enlarges to the size of a ten's egg, ought not to be confounded with any strict joint disease. If the position of the knee be fixed, we should inquire whother this begin with acute disease, what may be the present chances of anchylosis or of synostosis, and whether the hamstring tendons are more rigid than usual. It is an excellent point in diagnosis to make the condition of the smaller joints interpret that of the larger, hecause the qual ty of the morbid change in the former is obviously more easy of detection. I believe I am entitled to say that the fruit of much careful investigation is to confirm the theory that there are some cases which are really compounded of gout and rheumatism, which have both elements plainly in their history, and which may be truly called instances of "rheumatic gout" in this sense and no other. Dr. Garrod describes an acute type of rheumatoid arthritis Would it not be simpler to put the matter thus?--that an acute neural phase sometimes merges into a long subfebrile one, which may itself be accentuated now and then by transient mental and bodily influences. In our hospital practice we should be relieved from embarrassment if all the medical reports supplied with the patients were accurate and full. Acknowledging with thanks the time and trouble bestowed upon many of these reports, in not a few "rheumatism" does duty for diverse maladies; the history meagrely given, and obvious disqualifications are passed over; and as to treatment, we are enlightened with the in telligence that it has been "usual " or "various." Lately a man was admitted under the guise of "chronic rheumatism" when he was undoubtedly suffering from locomotor ataxy.

It is the business of the physician to try to discriminate real things from their analogies and counterfeits; and although the three type-forms I have described occupy most of our attention among private and hospital patients, we shall slip into pitfalls unless we bear in mind several otber morbid conditions which are sure to occur. There are the neuro-mimeses, with their psendo-pains, swellings, and genuine contractures: part of that "variety of masquerade" which is the property of hysteria. There are the remarkable phenomena of tabetic arthropathy, or that destructive and painless joint affection which occasionally happens in the subjects of locomotor ataxy ; ${ }^{4}$ and there are supposed to be allied forms of arthritis in other diseases of the cerebro-spinal axis. The pyæmic affections wlich are the sequel of scarlatina, gonorrhoea, and certain other diseases, often bring serious mischief to joints, and some may remain permanently crippled. Joints may be malformed by the contractures of paralysis, and by the consequences of muscular atrophy or spasm; nor should we forget the effects of natural senile change. In all doubtful circumstances, inquiry ought to be made about past dislocation, or any kind of violence which long ago may have damaged the epiphyses of the long bones. All these are so many mind-pictures which the practitioner must carry ahout with him, if he wishes to guard against a rash diagnosis and a wrong treatment.

Out of the wealth of clinical material which the Mineral Water Hospital constantly supplies, I have constructed a new grouping of the forms of chronic arthritis, simply as an attempt to interpret the facts which come before us without the bias of preconceived theories. The following classifica. tion is proposed :- (a) Rheumatic arthritis. (b) Gouty artbritis. (c) Nodular (or rheumatoid) arthritis. (d) Hybrid arthritis of gout and rheumatism, the proper "rheumatic gout." (e) The slow residual arthritis after acute inflammation, whether this be traumatic or qursi-idiopathic. (f) Pyæmic artbritis. (g) Strumous arthritis, includiog synovial arthritis and medullar arthritis. (h) Sypbilitic arthritis. (i) Tabetic or ataxic arthritis. (j) Neural arthritis of hysteria and its congeners. Combinations of two or more of these states are conceivahle, and mav require much sag xcity to unravel. The problem is almnst al ways as much medical as chiruroical. In any given patient the vital force of the system must he considered; and this general formula includes the textural soundnees of the heart, the activity of the liver, the chemical reactions of the urine, and the functional quietness of the skin. All these points are aids to diaguosis, and guides to the particular course which our treatment should take.

In another paper I propose to show to what extent the Bath thermal waters appear to be the rapeutical in the several forms

4 A communication by M. Debove to the Société Médicale dea Hôpitaux shows that the bone changes observed in locomntor ataxy art to be found also in some cases of old hemiplegia. (THE LAYCET, as inadvertently admitted into the Buth Mineral Water Hospital ther was a short rib-shaped substance of the consistence of despeal, there over the lower border of the right gluteus maximus muscle. over the lower border of the right gluteus maximus muscle. I was
much puzzled by this curiosity, and could not recall any similar case much puzzled by this curiosity, and could not recall any similar case some remarks by Dr. Buzzard at the Pathological Society of chance some remarks by Dr. Buzzard at the Pathological Society of London nine inches long, developed in the superior tendon of the rectus femoris muscle" of a patient suffering from tabes dorsalis. My personal muscle of a patient suffering from tabes dorsalis. My personal know: ledge of tabetic arthropathy is limited to the not very well-market symptoms of a single case. If I understand rightly the views of Charent joints ou ars quion. 
of arthritis. Meanwhile let me say that the Bath Mineral Water Hospital affords an almost unrivalled field of observation for the study of many diseases of the joints, and far too little seems to be known of the variety of its clinical re. sources. There are no out-door patients, and we shall be only too glad to meet medical men at our daily in-door clinique between twelve and one o'clock. Some prejudices may, perhaps, be removed respecting our Mineral Waters and their honourable traditions in the treatment of chronic disease; and in return we may get from our visitors, especially from those who minister in the large hospitals of great cities, some noteworthy experience on those types of arthritis which are associated with neurotic influences. Diseases of the joints are a much larger subject than was imagived ten years ago, and they will amply reward a thoughtful study. Bath.

REMARKS ON

\section{EPITHELIOMA AND ICHTHYOSIS OF THE TONGUE, BASED ON THE RECORDS OF SEVENTY-FIVE CASES.}

By HENRY MORRIS, M.A., F.R.C.S., SURGEON TO, AND LECTURER ON SURGERY AT, THE MIDDLESEX HOSPITAL.

(Concluded from page 81\%.)

ICHTHYOSIS OF TONGUE AND ORAL MUCOUS MEMBRANE.

THERE are fourteen cases of ichthyosis unassociated with cancer in Table 3, and thirteen cases associated with cancer in Tables 1 and 2. In sixteen out of the twenty. seven cases the tongue alone was affected, in seven cases the buccal mucous membrane as well as the tongue, and in four the buccal membrane, but not the tongue. The characters of ichthyosis were not the same in all the cases. Three different elinical types of the disease may be described. First, the pearly white, or bluish-white, and tesselated variety, in which the surface is more or less delicately furrowed, and more or less smooth in appearance; though, when dry at least, it is generally harsh, if not actually rough to the finger. A considerable part of the anterior half or two thirds of the dorsum are usually affected. This is the commonest form. For convenience it might be called the smooth tesselated variety. Secondly, the milky-white, raised plaque; varying in size from a split pea to a split walnut. It is harsh, even horny, to the touch when dry; though when moistened with saliva it may have a sodden appearance, like a piece of wet white kid glove. Either the papillæ may be enlarged, and the plaque appear to be formed by the papillæ, or the whole plaque may simply look like a very thick layer or layers of white epithelium. This is the form of the disease which has tempted some who have been the subject of it to shave it off from time to time. It may be conveniently called the raised plaque variety. Thirdly, a thick yellowish or yellowish-white fur overlies the largely hypertrophied papillæ; the papillæ are thickly set one against the other, and capable of being made to stand erect by the finger-nail; elsewhere the surface of the tongue may have the pearly-white and tesselated appearance. This may properly be called the papillomatous variety. These forms may be found separately, or together in the same individual, Cancer may be associated with either form singly, or with all combined. In a case ${ }^{1}$ shown to me by Dr. Lediard (and therefore not included in the table), there was a large papillomatous tumour associated with the second or raised plaque variety.

Antecedent habits. - Each of the forms of ichthyosis occurs in those who have had syphilis, as well as in those who have not; in great smokers, as we! 1 as in those who have only smoked moderately or but little ; in those who have drunk freely of raw spirits, as well as in those who deny having done so. In twelve cases syphilis bad been contracted at some period varying from four to thirty years before the patient came under notice. In six there had been nosypbilis. In the remaining nine either there is no record of syphilis or it was doubtful. In several of the cases with a history of syphilis

1 A coloured drawing of this case, as well as others of each of the three types of the disease, were shown to the Society. the ichthyosis was noticed within a year or two after the syphilitic infection. Eight patients confessed to excessive drinking, and some had been in the habit of taking raw spirits in large quantities, or perhaps it would be more correct to say in small quantities frequently. Nine were great smokers, and two are described as moderate smokers. The free drinkers were for the most part the great smokers. Six of the great smokers had also had syphilis; two of them denied having had this disease.

Thus it appears that ichthyosis is no more invariably preceded by a combination of syphilis and the habits of smoking and drinking, or by either of these conditions separately, than these conditions, separately or combined, are invariably followed by ichthyosis. Patients have occasionally attributed the ichthyosis to $f_{1}$ iction against a tooth, or to the pressure and friction of the plate of artificial teeth. I have seen in one instance (the case of a gentleman not included in the tables) in which the mucous membrane of the gums and floor of the mouth was the seat of ichthyosis of the raised plaque variety, epithelioma developed on the part to which a plate had rested; but the ichthyosis had preceded the wearing of the plate.

I have several times seen the smooth and the raised varieties of ichthyosis develop on the stump of the tongue after excision for cancer. In one of the cases which $I$ formerly recorded ${ }^{2}$ this had already happened; in the second of those cases it subsequently occurred. The same thing takes place on the mucous surface of other parts besides the mouth. I have observed it on the inner surface of the vulva after excision of an epitheliomatous ulcer. The patient was seventy-five years of age, and when the wound healed, which it did rapidly, there was on the cicatrix a raised white patch the size of a threepenny piece, which was typically like the so-called ichthyosis glossæ. There were one or two other patches on the lower part of the vagina, above the seat of operation.

In some of the persons who have had syphilis the ichthyotic condition is possibly the result of the cicatrisation of superficial ulcels. Probably cicatrisation after any form of ulcer or wound in persons of a particular tendency may produce ichthyosis of the part; and probably. too, this is more likely to occur in those who have a predisposition to epithelial cancer. I have not noticed that as a trequest occurrence the persons affected witt ichthyosis have been gouty, rheumatic, or affected with arthritic troubles, as MM. Bazin and Debove have found.

When at Montpellier, last summer, I was struck with a drawing which looked like a representation of the smooth form of ichthyosis in a fissured syphilitic tongue. It was, however, intended to show the result of the changes wrought on the tongue by pellagra, a disease which, it seems, is little or not at all heard of in this country, but which is common in the district of Les Grandes Landes and Italy, and has been seen from time to time in several other countries of Europe. It is a disease which expends itself on the skin, the tongue, digestive tract, and the nervous system, and is attributed to a diet composed too exclusively of imprect or blighted maize. As it affects the tongue, pellegra is an extremely aggravated form of the morbid changes which, in a slight degree, are brought about by simpler disturbances of the digestive functions.

Sex - Probably one of the strongest arguments in favour of the opinion that smoking and spirit drinking conduce to ichthyosis is the great preponderance of males over females who are affected with it. Out of twenty-seven cases twentytwo were males; and one at least of the women had smoked for many years and had also had syphilis.

Age. - The age at which ichthyosis commences is uncertain, but in several cases it was before the thirty-fifth year. The ages of the patients when they first came under observation varied from thirty-two to sixty-seven, the average being a little over fifty-one years of age. There were three under forty years ; three between forty and fortyfive ; six between forty-five and fifty ; nine between fifty and sixty ; six between sixty and seventy. When the number of jears during which the disease had existed was taken into account, it appeared that the average age at the time of commencement was a little less than forty.two years and a half. In sixteen cases in which the duration of the disease was stated the age of the patients at the time of its recognition was in five between thirty and thirty-five; in two between thirty-five and forty; in four between 